\title{
Absence of Germline BRCA1 c.68_69delAG and c.5266dupC Mutations among Hormone Receptor-negative Breast Cancer Patients: A First Impression at a Tertiary Cancer-care Facility in Tanzania
}

Linus P Rweyemamu ${ }^{1,2} *$, Gokce Akan ${ }^{3,4}$, Christopher H Mbotwa ${ }^{2}$, Nazima Dharsee ${ }^{5}$, Lucy A Namkinga ${ }^{1}$, Sylvester L Lyantagaye ${ }^{1,2}$, Ted F Mselle ${ }^{3}$ and Fatmahan Atalar ${ }^{3,6}$

${ }^{1}$ Department of Molecular Biology and Biotechnology, University of Dar es Salaam, P.O. Box 35179, Dar es Salaam, Tanzania.

${ }^{2}$ Mbeya College of Health and Allied Sciences, University of Dar es Salaam, P.O. Box 608, Mbeya, Tanzania.

${ }^{3}$ Department of Biochemistry, Genetic Laboratory, Muhimbili University of Health and Allied Sciences, P.O. Box 6500, Dar es Salaam, Tanzania.

${ }^{4}$ Research Center of Experimental Health Sciences (DESAM), Near East University, P.O. Box 99138, Nicosia, Cyprus.

${ }^{5}$ Academic, Research and Consultancy Unit, Ocean Road Cancer Institute, P.O. Box 3592, Dar es Salaam, Tanzania.

${ }^{6}$ Department of Rare Diseases, Child Health Institute, Istanbul University, Istanbul, 34093, Turkey.

*Corresponding author's e-mails: linuspaul88@gmail.com; paul.linus@udsm.ac.tz (LPR), Co-authors'e-mail addresses: akangokce@yahoo.com (GA); cmbotwa@udsm.ac.tz (CHM); njdharsee@gmail.com (ND); odulajalucy@yahoo.com (LAN); lyantagaye@gmail.com (SLL); tedmselle@gmail.com (TFM); fatmahan.atalar@gmail.com (FA)

Received 8 Oct 2021, Revised 26 Nov 2021, Accepted 20 Dec 2021, Published Dec 2021 DOI: https://dx.doi.org/10.4314/tjs.v47i5.27

Abstract
The germline BRCA1 c.68_69delAG (185delAG) and c.5266dupC (5382insC) mutations are
associated with hormone receptor-negative breast cancer (BC). Limited studies have examined
their contribution to alarming BC incidence in Sub Saharan Africa (SSA). Our study aimed to
examine the contribution of germline BRCA1 c.68_69delAG and c.5266dupC mutations to BC
incidence among hormone receptor-negative BC patients admitted to Ocean Road Cancer
Institute in Tanzania. Face-to-face interviews were conducted to capture socio-demographic
characteristics, anthropometric measurements, family history of cancer and reproductive
information from each patient. Their histopathological data were extracted from the hospital
medical records. The germline BRCA1 founder mutations were analyzed on blood samples
using Sanger sequencing technology. The patients mean age at diagnosis was $47.05 \pm 12.82$
years. A family history of cancer was observed in $13.6 \%$ of patients. The germline BRCA1
c.68_69delAG and c.5266dupC mutations were not detected in the study group. Our findings
indicate that the germline BRCA1 c.68_69delAG and c.5266dupC mutations do not contribute
to BC manifestation in hormone receptor-negative BC patients in Tanzania. Thus, screening BC
patients for these mutations has no clinical relevance. Our data further suggest that the
c.68_69delAG and the c.5266dupC mutations should not be considered when developing
genetic testing guidelines in Tanzania.

Keywords: Breast cancer, germline BRCA1 mutation, c.68_69delAG (185delAG), c.5266dupC (5382insC), Tanzania.

1824 


\section{Introduction}

Breast cancer (BC) is the most commonly diagnosed $(24.5 \%)$ and the leading cause of mortality $(15.5 \%)$ among women worldwide (Sung et al. 2021). Recently, developing countries, including Sub Saharan Africa (SSA), recorded rapidly increasing $\mathrm{BC}$ incidences accompanied by higher mortality of about $17 \%$ compared to developed countries (Sung et al. 2021). In Tanzania, the incidence rate of $\mathrm{BC}$ has rapidly increased over the past two decades. It is estimated that by 2030 , the rate will exceed $80 \%$ (Komen 2017). Currently, BC is ranked as the second most cause of cancer deaths among women after cervical cancer in Tanzania (Komen 2017, Sung et al. 2021).

The etiology of $\mathrm{BC}$ is still unclear, however, several risk factors ranging from genetic, hormonal, and environmental factors have been described (Nickels et al. 2013, Anyigba et al. 2021). About 5-10\% of BC cases are attributed to genetic predisposition, resulting from germline mutations in one or multiple genes, including $B R C A 1, B R C A 2$, TP53, PTEN, CHEK2, PALB2, BARD1, ATM, and RAD51 (Shin et al. 2020). Germline mutations in BRCA1 and BRCA2, the two major high-penetrance cancer susceptibility genes, indicate an increased lifetime risk of $\mathrm{BC}$ and ovarian cancer (OC). Women harboring deleterious mutations in these two genes have up to $85 \%$ BC risks and up to $60 \%$ OC risks (Pogoda et al. 2020). Primarily, $B R C A 1$ and $B R C A 2$ are involved in genome integrity maintenance through mediating double-strand break DNA repair via homologous recombination. Also, these genes are involved in several cellular processes such as regulation of apoptosis, cell cycle progression, and transcription (Miki et al. 1994, Wooster et al. 1995).

The BRCA1 (OMIM\# 113705) located on chromosome $17 \mathrm{q} 21.31$ was initially described in the early 1990 s by linkage analysis and later by positional cloning as a cancer susceptibility gene (Hall et al. 1990, Miki et al. 1994). This gene consists of 24 exons, of which 22 exons code for a $220 \mathrm{kDa}$ functional protein of 1863 amino acids (Chen et al. 1996). Several studies across the globe describe an array of loss of function germline mutations in the BRCA1. The common germline mutations within this gene are the c.68_69delAG (185delAG) located in exon 2 and the c.5266dupC (5382insC) located in exon 20. The two germline mutations were first described as founder mutations in Ashkenazi Jews (Roa et al. 1996), though they are also reported in other ethnic groups in Europe (Hartwig et al. 2013, Pogoda et al. 2020), Asia (Chakraborty et al. 2013), America (Ewald et al. 2011, Rummel et al. 2017), and Northern Africa (Abdel-Mohsen et al. 2016, Abou-El-Naga et al. 2018, Mahfoudh et al. 2019). Individuals harboring these mutations are at elevated risks of BC, OC, prostate cancer, and other cancers (Barrios et al. 2017).

The c.68_69delAG is described as among the two Ashkenazi BRCAl founder mutations. This is a frameshift mutation that involves deletion of adenine and guanine at position 185 of exon 2 resulting to the creation of a stop codon, hence a premature termination of translation and truncated protein occurs (Hartwig et al. 2013). The c.5266dupC, being the second BRCAl Ashkenazi founder mutation, is also a frameshift mutation in which there is an insertion of a cytosine at position 5382 of exon 20, resulting in the production of premature truncated nonfunctioning protein (Mogahed et al. 2020).

The hormone receptor-negative $\mathrm{BC}$ accounts for up to $50 \%$ of BCs in Tanzania (Burson et al. 2010, Mwakigonja et al. 2017). This group includes the triple-negative and the HER-2 enriched subtypes which are characterized by rapid growth, poor prognosis, and are known to be highly aggressive subtypes (Eng et al. 2014). The hormone receptor-negative group lacks expressions of the estrogen receptor (ER) and the progesterone receptor (PR), the molecules that dictate hormonal therapy (Waks and Winer 2019). However, this form of BC cannot be treated with targeted drugs commonly used to treat other types of $\mathrm{BC}$, such as tamoxifen and aromatase inhibitors for hormone receptor-positive BC (Waks and Winer 2019). Therefore, ER and PR-negative patients have limited treatments in Tanzania. 
It is known that germline mutations in $B R C A 1$ are common in patients with hormone receptor-negative $\mathrm{BC}$. Although, the mutations causing the progression of those patients have not been fully elucidated (Adedokun et al. 2020). According to studies in Caucasians and Arabs, BC patients harboring either of the c.68_69delAG, the c.5266dupC, or other germline BRCA1 deleterious mutations are associated with early-onset of the disease, high-grade tumors, estrogen and progesterone hormone receptorsnegative subtype (ER- and PR-), and bilaterality (Szwiec et al. 2015, Mahfoudh et al. 2019). Characterization of germline BRCAl deleterious mutations is not well established in majority of oncology centers in SSA, despite few studies from South Africa (Francies et al. 2015), Rwanda (Uyisenga et al. 2020) and Burkina Faso (Zoure et al. 2018). Thus, their contribution to alarming BC incidence among indigenous (black) Africans is not clearly known. Therefore, in this study, we applied Sanger sequencing to investigate the contribution of the c.68_69delAG and the c.5266dupC mutations in $\mathrm{BC}$ manifestation among $81 \mathrm{BC}$ patients diagnosed with hormone receptor-negative $\mathrm{BC}$ in Tanzania. Elucidating the prevalence of these germline BRCA1 mutations in hormone receptor-negative $\mathrm{BC}$ patients is important in establishing affordable, cost-effective genetic counseling and testing, and establishing individualized $\mathrm{BC}$ preventive and treatment measures among the indigenous African population.

\section{Materials and Methods \\ Study population}

This cross-sectional descriptive study was conducted at Ocean Road Cancer Institute (ORCI), the only public tertiary cancerspecialized facility in Dar es Salaam, Tanzania. We approached the BC patients referred to the facility for radiation therapy, endocrine therapy, immune therapy, and palliative care between September 2019 and May 2021. Inclusion criteria based on a patient being indigenous Tanzanian with a complete histopathological report in the hospital records showing the ER and the PR- negative statuses. Only hormone receptornegative patients were selected because they comprise the triple-negative and the HER-2 enriched BC subtypes. Patients belonging to these subtypes do not benefit from endocrine therapy, the most available therapeutic option in many oncology centers in SSA. Hormone receptor-positive patients, non-indigenous Tanzanians, other nationalities, and $\mathrm{BC}$ patients with incomplete histopathological reports were excluded.

The sample size for prevalence crosssectional studies given by $n=z^{2} P(1-P) / d^{2}$ was used; where; $\mathbf{n}$ is the minimum sample size required, $\mathbf{z}$ is the critical value for the given confidence level, $\mathbf{P}$ is the expected prevalence based on previous studies, and $\mathbf{d}$ is the margin error (Charan and Biswas 2013). For this study, $\mathbf{z}$ was 1.96 (based on $95 \%$ confidence level), $\mathbf{P}$ was 0.055 (5.5\%), and $\mathbf{d}$ was 0.05 $(5 \%)$. These parameters gave the minimum sample size of 80 . We included 81 patients who met the inclusion criteria and their clinical data on BC presentation, diagnosis, staging, and others were extracted from patients' hospital records.

Face-to-face interviews were conducted to capture the patient's socio-demographic characteristics, anthropometric measurements, family history of cancer, and reproductive behavior information. Peripheral blood (5 $\mathrm{mL}$ ) was collected from the antecubital vein of each participant and stored in EDTA-tubes until used for DNA extraction. The study was approved by the Ethics Committee of the Tanzania National Institute for Medical Research (NIMR) permit no. NIMR/HQ/R.8a/Vol. IX/3255, and the ORCI Institution Review Board permit no. 10/Vol/XX/16. We also obtained written informed consent from each of the study participants.

\section{DNA isolation and quantification}

The genomic DNA was isolated from peripheral blood leucocytes using the High Pure PCR Template Preparation Kit as per manufacturer's recommendations (ref\# 11796828001), Roche life science, Germany. DNA integrity was checked by agarose gel electrophoresis. The quantity and quality were 
determined using Nanodrop ${ }^{\mathrm{TM}} 2000$ Spectrophotometer (Thermo Scientific).

\section{Amplification and gel electrophoresis}

The BRCA1 exon 2 and 20 were amplified in a final volume of $50 \mu \mathrm{L}$ containing: $50 \mathrm{ng}$ genomic DNA, $25 \mu \mathrm{L}$ OneTaq Quick-load 2X Master Mix with Standard Buffer (NEB), and $1 \mu \mathrm{L}$ of $10 \mu \mathrm{M}$ each forward and reverse primer. The primers for the c.68_69delAG in exon 2 and the c.5266dupC in exon 20 mutations were adopted from Chowdhury et al. (2020) and Mahfoudh et al. (2019), respectively, and are given in Table 1 . The primers for both exons were designed to anneal within the exon-intron boundaries of both 5' and '3' ends. The targeted DNA segments were amplified by a conventional polymerase chain reaction (PCR) on a BioRad T100 TM Thermal Cycler (Germany). The PCR conditions for exon 2 amplification consisted of an initial denaturation for 5 minutes at $95{ }^{\circ} \mathrm{C}$, followed by 34 cycles of 95 ${ }^{\circ} \mathrm{C}$ for 1 minute, $57{ }^{\circ} \mathrm{C}$ for 25 seconds, and 72 ${ }^{\circ} \mathrm{C}$ for 30 seconds; then a final extension at 72 ${ }^{\circ} \mathrm{C}$ for 5 minutes. The thermo-cycling conditions for exon 20 amplification consisted of an initial denaturation for 5 minutes at $95{ }^{\circ} \mathrm{C}$, followed by 34 cycles of 95 ${ }^{\circ} \mathrm{C}$ for 30 seconds, $52{ }^{\circ} \mathrm{C}$ for 30 seconds, and $72{ }^{\circ} \mathrm{C}$ for 30 seconds; then a final extension at $72{ }^{\circ} \mathrm{C}$ for 5 minutes. The PCR amplicons were confirmed by running on ethidium bromide-stained $1.5 \%$ agarose gel electrophoresis.

Table 1: The description of primers used for PCR and Sanger sequencing

\begin{tabular}{lllll}
\hline $\begin{array}{l}\text { BRCA1 } \text { exon } \\
\text { (target mutation) }\end{array}$ & $\begin{array}{l}\text { Primer } \\
\text { name }\end{array}$ & Sequence 5'---->3' & Length & $\begin{array}{l}\text { Product } \\
\text { size (bp) }\end{array}$ \\
\hline Exon 2 & Ex2_F & GGACGTTGTCATTAGTTCTTTGGT & 24 & 330 \\
(c.68_69delAG) & Ex2_R & TCCCTAGTATGTAAGGTCAATTCTG & 25 & \\
Exon 20 & Ex20_F & ATATGACGTGTCTGCTCCAC & 20 & 259 \\
(c.5266dupC) & Ex20_R & AGTCTTACAAAATGAAGCGG & 20 & \\
\hline
\end{tabular}

\section{DNA purification and sequencing}

The PCR amplicons were purified using an ExoSAP-ITTM PCR Product Cleanup Reagent (Applied Biosystems, CA, USA), as per the manufacturer's recommendations. Sequencing reactions were performed bidirectionally using BigDye ${ }^{\circledR}$ Terminator v3.1 Cycle Sequencing Kit (Applied Biosystems, CA, USA) on an ABI 96-capillary 3730xl DNA Analyzer (Applied Biosystems, CA, USA).

\section{Data analysis}

In each of the 81 samples analyzed, fourcolor chromatogram Sanger sequence reads were obtained from both forward and reverse sequencing primers. The sequences were manually inspected then trimmed using DNA Baser Assembler 5.15 and a consensus sequence generated. To identify the c.68_69delAG and the c.5266dupC mutations in BRCAl exon 2 and 20, respectively, the generated consensus sequences were aligned to the BRCAl reference sequence (NG_005905.2) retrieved from National
Center for Biotechnology Information using MEGA-X v6 software. BC patients' sociodemographic characteristics and clinicalpathological data were analyzed using the IBM Statistical Package of Social Sciences v.25.0 (IBM SPSS, Inc., Chicago, IL, USA). Categorical variables were defined by their absolute frequencies and percentages, whereas quantitative variables were expressed as mean and standard deviation (SD).

\section{Results}

A total of $81 \mathrm{BC}$ cases were included in the present study. All patients were indigenous Tanzanians. The mean age of the patients \pm SD were $49.32 \pm 13.05$, while the mean age at $\mathrm{BC}$ diagnosis \pm SD were $47.05 \pm$ 12.82 years. Only $11(13.6 \%)$ BC patients reported a family history of cancer in their first and second-degree relatives. Five patients $(6.2 \%)$ had bilateral tumors, 34 $(42.0 \%)$ had a tumor on the left and 42 (51.9\%) on the right breast. Regarding the clinical characteristics of the participants, the majority $(76.6 \%)$ of them were diagnosed at 
late stages (stage III and IV). A large proportion $(86.4 \%)$ of the patients were diagnosed with invasive ductal carcinoma of no specific type. HER-2 expression was negative in $65.4 \%$ and positive in $34.6 \%$ of participants (Table 2).

Table 2: Socio-demographic and clinical characteristics of the studied BC patients

\begin{tabular}{|c|c|c|c|}
\hline \multicolumn{2}{|l|}{ Characteristics } & Number, $\mathrm{n}$ & Percentage, $\%$ \\
\hline \multicolumn{2}{|c|}{ Age at diagnosis (Mean \pm SD) } & \multicolumn{2}{|l|}{$47.05 \pm 12.82$} \\
\hline & Below 40 & 16 & 19.8 \\
\hline & $40-49$ & 33 & 40.7 \\
\hline & Above 49 & 32 & 39.5 \\
\hline \multirow[t]{4}{*}{ Occupation } & Peasant & 42 & 51.9 \\
\hline & Entrepreneur/Business & 17 & 21.0 \\
\hline & House wife & 18 & 22.2 \\
\hline & Other & 4 & 4.9 \\
\hline \multirow[t]{3}{*}{ Marital status } & Current married & 52 & 64.2 \\
\hline & Never married & 8 & 9.9 \\
\hline & Previous married & 21 & 25.9 \\
\hline \multirow{7}{*}{ Zone of origin } & Central & 11 & 13.6 \\
\hline & Eastern & 15 & 18.5 \\
\hline & Lake & 7 & 8.6 \\
\hline & Northern & 16 & 19.8 \\
\hline & Southern highlands & 15 & 18.5 \\
\hline & Southern & 10 & 12.3 \\
\hline & Western & 7 & 8.6 \\
\hline \multirow[t]{4}{*}{ BMI } & Under weight & 3 & 3.7 \\
\hline & Normal & 30 & 37.0 \\
\hline & Over weight & 22 & 27.2 \\
\hline & Obese & 26 & 32.1 \\
\hline \multirow{5}{*}{$\begin{array}{l}\text { Family history of } \\
\text { cancer } \\
\text { Laterality }\end{array}$} & Yes & 11 & 13.6 \\
\hline & No & 70 & 86.4 \\
\hline & Left & 34 & 42.0 \\
\hline & Right & 42 & 51.9 \\
\hline & Bilateral & 5 & 6.2 \\
\hline \multirow{5}{*}{$\begin{array}{l}\text { TNM pathological } \\
\text { stage }\end{array}$} & Stage I & 1 & 1.2 \\
\hline & Stage II & 9 & 11.1 \\
\hline & Stage III & 42 & 51.9 \\
\hline & Stage IV & 20 & 24.7 \\
\hline & Unspecified & 9 & 11.1 \\
\hline \multirow[t]{4}{*}{ Histological type } & Invasive Ductal Carcinoma & 70 & 86.4 \\
\hline & Invasive Lobular Carcinoma & 5 & 6.2 \\
\hline & Mucinous Carcinoma & 1 & 1.2 \\
\hline & Unspecified & 5 & 6.2 \\
\hline \multirow[t]{2}{*}{ HER-2 status } & Negative & 53 & 65.4 \\
\hline & Positive & 28 & 34.6 \\
\hline Alcohol & Yes & 15 & 18.5 \\
\hline \multirow{3}{*}{$\begin{array}{l}\text { consumption } \\
\text { Menstrual phase }\end{array}$} & No & 66 & 81.5 \\
\hline & Post-menopausal & 43 & 53.1 \\
\hline & Pre-menopausal & 38 & 46.9 \\
\hline \multirow[t]{2}{*}{ Contraceptives use } & Yes & 34 & 42.0 \\
\hline & No & 47 & 58.0 \\
\hline \multirow[t]{2}{*}{ Ever been pregnant } & Yes & 75 & 92.6 \\
\hline & No & 6 & 7.4 \\
\hline
\end{tabular}


SD: standard deviation; BMI: body mass index, given as weight $(\mathrm{kg}) /$ height squared $\left(\mathrm{m}^{2}\right)$; TNM: tumor node metastasis; HER-2: Human epidermal growth factor receptor-2.

Among these $81 \mathrm{BC}$ patients, none were found to carry either the c.68_69delAG or the c.5266dupC mutation in the BRCA1. See Figure 1.

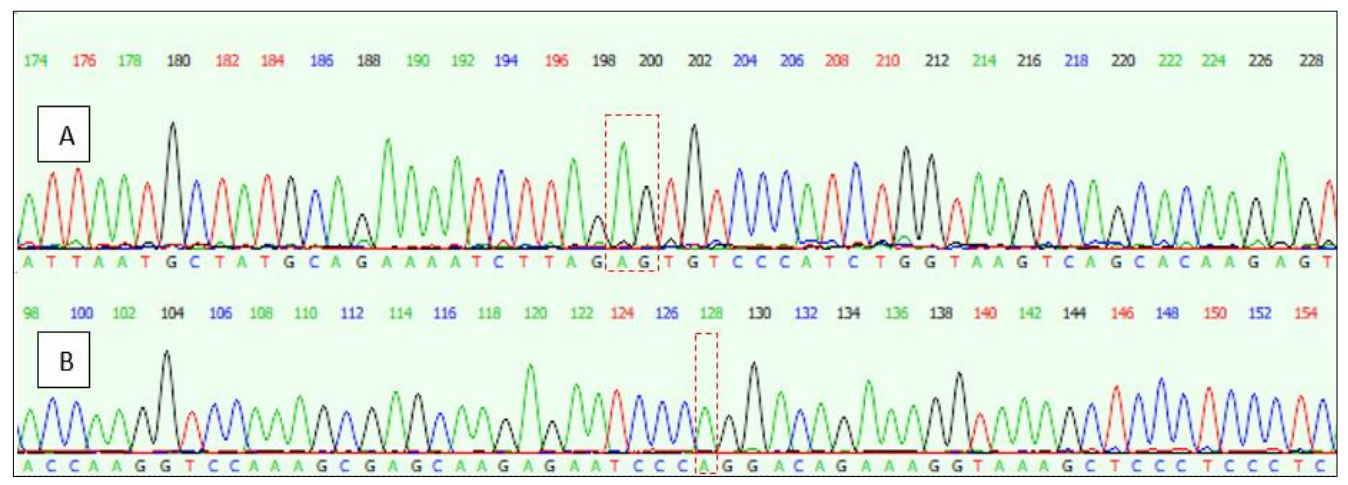

Figure 1: A representative Sanger sequence showing the analysis of $B R C A l$ founder mutations. Picture A shows the absence of the c.68_69delAG mutation at positions 199-200 and Picture B shows the absence of the c.5266dupC mutation at position 127.

\section{Discussion}

Genetic screening for germline BRCA1/2 mutations, which its database serves as a cornerstone towards developing a relatively cheaper ethnic-based BRCAl/2 screening panel, is gaining significant acceptance in clinical settings worldwide. In some developed countries, it has been integrated into the $\mathrm{BC}$ investigations and management practices. Guidelines have been developed that give the roadmap of how risk assessment, genetic screening and counseling can be achieved at different levels (Balmana et al. 2011, Huang et al. 2019). However, in most SSA countries, genetic screening still has a long way to be achieved in clinical settings. Limited studies report the prevalence and spectrum of BRCA1/2 germline mutations in SSA populations. Therefore, the database for $B R C A 1 / 2$ germline mutations is still at infant level or does not exist in most countries in SSA.

Sanger sequencing and the NextGeneration Sequencing (NGS) are regarded as the "gold standard" genetic screening technologies in molecular diagnostics of BC and other cancers. Several protocols have been developed and made commercially available to ease genetic testing (Gill et al. 2018). The developed protocols take advantage of already established BRCA1/2 mutations databases and the ongoing intense BRCA1/2 mutations researches across different ethnic groups. However, the results seem to vary between studies. Due to lack of $B R C A 1 / 2$ mutation databases, inadequate resources to procure the kits, machines, and limited technical personnel, genetic testing and counseling services are not commonly provided in most of SSA hospitals or oncology centers (Anyigba et al. 2021). In an attempt to understand the first impression of the contribution of the germline BRCAI c.68_69delAG (185delAG) and c.5266dupC (5382insC) mutations to alarming BC incidences in Tanzania, we applied Sanger sequencing technology to analyze the c.68_69delAG and the c.5266dupC mutations located within the exon 2 and exon 20 of the $B R C A 1$, respectively, in a series of 81 hormone receptor-negative $\mathrm{BC}$ patients. The initial genetic screening of the germline $B R C A 1$ founder mutations before investigating the entire coding regions is considered a time and cost-effective approach in developing ethnic-specific genetic screening guidelines/tools. This is well established in European countries, Brazil, the USA, Asia, and Latin America. Poorresources countries like Tanzania have to 
adopt this approach to understand the contribution of the germline BRCAI mutations to alarming $\mathrm{BC}$ incidence.

This study is, to the best of our knowledge, the first study to analyze the germline BRCAl mutations in hormone receptor-negative BC patients in Tanzania. None of the 81 patients carried either the c.68_69delAG (185delAG) or the c.5266dupC (5382insC) germline mutations. The absence of BRCAl germline mutation observed in this study suggests that the c.68_69delAG and the c.5266dupC mutations are not present or might be present at extremely low frequencies among indigenous Tanzanian BC patients. Our findings relate with previous findings from Eastern Iran that reported the absence of these mutations; where other mutations in exons 11,13 , and 16 were detected in a series of 88 patients (Khalili-Tanha et al. 2019). Similarly, a study from north-central Poland reported that the c.68_69delAG mutation was rare in their population, detected only in one out of 252 BC patients screened. Consequently, Hartwig et al. (2013) recommended that the c.68_69delAG mutation should not be part of the primary BRCAl screening test in the population of north-central Poland.

Contrary to our findings, a study from Northern African country, Egypt, reported an appreciable frequency of the c.68_69delAG and the c.5266dupC mutations in their study cohort comprised of three groups: the BC patients, their first-degree relatives, and a control group. Both mutations were observed in all the three groups, with the c.5266dupC mutation being distributed almost equally between the BC patients and a control group. This distribution eventually led to the speculations that only the c.68_69delAG mutation contributed to the $\mathrm{BC}$ incidence among Egyptian women (Abou-El-Naga et al. 2018). Also, a study in another Northern African country, Morocco, reported for the first time the presence of the c.68_69delAG mutation in females of two families (Zahra et al. 2011). These two studies provide evidence of the presence of the c.68_69delAG and the c.5266dupC mutations in the African population and might contribute appreciably to the $\mathrm{BC}$ incidence in North Africa. The detection of the BRCA1 c.68_69delAG and the c.5266dupC mutations in both cohorts can be explained by shared ancestry with the European and Middle East people (where these mutations have founder effect) because of a high possibility of migration of people to Morocco and Egypt. Therefore, we do speculate the existence of genetic flow between Northern African and European or Middle East people.

A case-control study in Uzbekistan involving $67 \mathrm{BC}$ patients with bilateral tumors, triple-negativity, family history of cancer, or early onset of the disease revealed the absence of the c.68_69delAG mutation in their analysis. Furthermore, this mutation was not detected in any of their 103 cancer-free control group. On the other hand, the same study reported a noticeable presence of the c.5266dupC mutation among $3(4.5 \%)$ patients and none in the control group. The authors concluded that the c.5266dupC mutation had a substantial contribution to $\mathrm{BC}$ incidences in Uzbek population. Hence, the c.5266dupC mutation was postulated to have the founder effect in their population (Abdikhakimov et al. 2016) similar to other European countries (Burcoş et al. 2013, Hartwig et al. 2013) and Southern American country, Brazil (Ewald et al. 2011).

There are several studies that analyzed the contributions of the c.68_69delAG mutation to BC incidences in different SSA populations. A preliminary study in Burkina Faso involving 15 unrelated patients with hereditary BC revealed the absence of this mutation (Zoure et al. 2018). Similar results were observed in an earlier study of 206 black women with BC from South Africa (Yawitch et al. 2000). Furthermore, Francies et al. (2015) using NGS technology, reported that none of the triple-negative/premenopausal black women BC patients in South Africa had the c.68_69delAG mutation, rather other mutations were detected in their analyses. On the other hand, a study in the same country by Reeves et al. (2004) detected a frequency of $4.4 \%$ of the c.68_69delAG mutation in patients of white/Ashkenazi Jewish ethnic background. 
The germline BRCA1 c.68_69delAG and c.5266dupC mutations are widely detected in many countries and considered as founder mutations in some sub-populations apart from the Ashkenazi ethnicity. The incidence varies considerably among ethnicities and the nature of study design (Tikhomirova et al. 2005, Hartwig et al. 2013, Pogoda et al. 2020, Gorodetska et al. 2021). A study involving Polish and Australian triple-negative BC patients indicated that c.68_69delAG and the c.5266dupC mutations contribute to $\mathrm{BC}$ incidences in their populations (Wong-Brown et al. 2015). Elsewhere in Asia, Chakraborty et al. (2013) reported a noticeable presence of c.5266dupC mutation with an incidence of $7.6 \%$ among the triple-negative $\mathrm{BC}$ patients. Chakraborty et al. (2013) recommended that genetic testing for this mutation in $\mathrm{BC}$ patients in their population is of great value.

The minority $(13.6 \%)$ of the patients analyzed for the c.68_69delAG and the c.5266dupC mutations in this study reported a family history of cancer. We could not confirm cancer history information given by patients, and in some cases this information may not be reliable, because cancers including $\mathrm{BC}$ seem to be new diseases to many indigenous Africans, especially those in rural areas. Reports show that a substantial number of women in SSA rural settings die with BC and other cancers undiagnosed, thus, cancer death rates statistics may not be realistic (Anyigba et al. 2021). In the current series, Invasive ductal carcinoma of no specific type (IDC-NST) was the most prevalent $(86.4 \%)$ histological type of breast tumors. These results relate with previous Tanzanian studies (Burson et al. 2010, Mwakigonja et al. 2017, Mansouri et al. 2019) and other East African studies (Galukande et al. 2014, Uyisenga et al. 2020).

In this series, we observed a massive number of women diagnosed of the disease at early age, with average age \pm SD of $47.05 \pm$ 12.82 years at $\mathrm{BC}$ diagnosis, and majority of them were at advanced stages (stages III and IV). These observations relate to the previous report of Mwakigonja et al. (2017) and slightly different to that of Mansouri et al. (2019). Taking together all these observations, there is an urgent need of increasing $\mathrm{BC}$ awareness campaigns at multiple occasions especially in rural settings of Tanzania.

A limitation of this study is that it focused on investigating the contribution of only germline BRCA1 c.68_69delAG and the c.5266dupC mutations to BC incidence among indigenous BC patients in Tanzania. The targeted Sanger sequencing approach used precluded the ability to detect other germline mutations in other exons of BRCAl and in other BC susceptibility genes such as BRCA2, CHEK2, and TP53 which are reported to play significant roles in $\mathrm{BC}$ predisposition in indigenous Africans (Uyisenga et al. 2020). The cross-sectional nature of study and the relatively small sample size of $81 \mathrm{BC}$ patients calls for a larger cohort studies in the future.

\section{Conclusion}

The results of this study pertain only to the germline BRCAl c.68_69delAG (185delAG) and c.5266dupC (5382insC) mutations in hormone receptor-negative $\mathrm{BC}$ patients. Nonetheless, the c.68_69delAG and the c.5266dupC mutations in BRCAl do not contribute to $\mathrm{BC}$ incidence among indigenous Tanzanians and perhaps other indigenous African populations in SSA. Therefore, the germline BRCAl mutations analyzed in this study have no role in $\mathrm{BC}$ manifestation in hormone receptor-negative $\mathrm{BC}$ patients in Tanzania, suggesting that screening patients with $\mathrm{BC}$ for these mutations could be of no clinical relevance.

Our cohort was relatively younger at BC diagnosis, suggestive of carrying pathogenic mutations in BC susceptibility genes. Therefore, these findings suggest that breast tumors in hormone receptor-negative patients may be attributed to other germline mutations in $B R C A 1$ or other germline mutations in genes such as BRCA2, CHEK2, PALB2, STK11, ATM, and TP53, or non-genetic factors. A larger study to analyze the complete coding regions of BRCAl and other $B C$ susceptibility genes for short-range mutations (single-nucleotide variation, insertions/duplication or deletions), and large- 
genomic rearrangements to unravel the causes of increasing BC incidence in the Tanzanian population is recommended.

\section{Acknowledgements}

The authors are grateful to all the $\mathrm{BC}$ patients at ORCI who volunteered to participate in this study. This work was supported by the University of Dar es Salaam (UDSM), Grant no: MCHAS-20131, and Tanzania Ministry of Education, Science, and Technology (MOEST) through 2018 MOEST fellowship to Linus Paul Rweyemamu.

\section{Conflict of Interest: None declared.}

\section{Ethical clearance and consent to participate}

The study was approved by the Institutional Review Board of Ocean Road Cancer Institute (reference number 10/Vol/XX/16), and Tanzania National Institute for Medical Research (NIMR) (reference number NIMR/HQ/R.8a/Vol.IX/3255). Also, all participants provided informed consent.

\section{References}

Abdel-Mohsen MA, Ahmed OA and El-Kerm YM 2016 BRCA1 gene mutations and influence of chemotherapy on autophagy and apoptotic mechanisms in Egyptian breast cancer patients. As. Pac. J. Cancer Prev. 17(3): 1285-1292.

Abdikhakimov A, Tukhtaboeva M, Adilov B and Turdikulova S 2016 The potential contribution of BRCA mutations to early onset and familial breast cancer in Uzbekistan. Cent. As. J. Global Health 5(1): 228.

Abou-El-Naga A, Shaban A, Ghazy H, Elsaid A, Elshazli R and Settin A 2018 Frequency of BRCA1 (185delAG and 5382insC) and BRCA2 (6174delT) mutations in Egyptian women with breast cancer compared to healthy controls. Meta Gene 15: 35-41.

Adedokun B, Zheng Y, Ndom P, Gakwaya A, Makumbi T, Zhou AY, Yoshimatsu TF, Rodriguez A, Madduri RK and Foster IT 2020 Prevalence of inherited mutations in breast cancer predisposition genes among women in Uganda and Cameroon. Cancer Epidemiol. Prev. Biomarkers 29(2): 359367.
Anyigba CA, Awandare GA and Paemka L 2021 Breast cancer in sub-Saharan Africa: The current state and uncertain future. Exp. Biol. Med. 246(12):1377-1387.

Balmana J, Diez O, Rubio I and Cardoso F 2011 BRCA in breast cancer: ESMO Clinical Practice Guidelines. Ann. Oncol. 22(6): 3134.

Barrios XG, Meseguer MDS, Vera MM, Bermúdez AIS, Cerrolaza JAM, Henarejos PS, Poves MZ, Hernández MRG, Tortosa EC and Baño ÁA 2017 Molecular characterization and clinical interpretation of BRCA1/BRCA2 variants in families from Murcia (South-Eastern Spain) with hereditary breast and ovarian cancer: clinical-pathological features in BRCA carriers and non-carriers. Famil. Cancer 16(4): 477-489.

Burcoş T, Cimponeriu D, Ion D, Spandole S, Apostol P, Toma M, Radu I, Popa I, Stanilescu S and Popa E 2013 Analysis of several BRCA1 and BRCA2 mutations in a hospital-based series of unselected breast cancer cases. Chirurgia 108(4): 468-472.

Burson AM, Soliman AS, Ngoma TA, Mwaiselage J, Ogweyo P, Eissa MS, Dey S and Merajver SD 2010 Clinical and epidemiologic profile of breast cancer in Tanzania. Breast Disease 31(1): 33-41.

Chakraborty A, Mukhopadhyay A, Bhattacharyya D, Bose CK, Choudhuri K, Mukhopadhyay S and Basak J 2013 Frequency of 5382insC mutation of BRCA1 gene among breast cancer patients: an experience from Eastern India. Famil. Cancer 12(3): 489-495.

Charan J and Biswas T 2013 How to calculate sample size for different study designs in medical research? Indian J. Psych. Med. 35(2): 121-126.

Chen Y, Farmer AA, Chen CF, Jones DC, Chen PL and Lee WH 1996 BRCA1 is a $220-\mathrm{kDa}$ nuclear phosphoprotein that is expressed and phosphorylated in a cell cycle-dependent manner. Cancer Res. 56(14): 3168-3172.

Chowdhury SS, Khatun M, Khan TH and Laila AB 2020 Mutation in Exon2 of BRCA1 Gene in Adult Bengali Bangladeshi Female Patients with Breast Cancer: An Experience from Two Tertiary-Care Hospitals. As. Pac. J. Cancer Prev. 21(8): 2265-2270.

Eng A, McCormack V and dos-Santos-Silva I 2014 Receptor-defined subtypes of breast 
cancer in indigenous populations in Africa: a systematic review and meta-analysis. PLoS Medicine 11(9): e1001720.

Ewald IP, Izetti P, Vargas FR, Moreira MA, Moreira AS, Moreira-Filho CA, Cunha DR, Hamaguchi S, Camey SA and Schmidt A 2011 Prevalence of the BRCA1 founder mutation c. 5266dupin Brazilian individuals at-risk for the hereditary breast and ovarian cancer syndrome. Hered. Cancer Clin. Prac. 9(1): 1-8.

Francies F, Wainstein T, De Leeneer K, Cairns A, Murdoch M, Nietz S, Cubasch H, Poppe B, Van Maerken T and Crombez B 2015 BRCA1, BRCA2 and PALB2 mutations and CHEK2 c. 1100delC in different South African ethnic groups diagnosed with premenopausal and/or triple negative breast cancer. BMC Cancer 15(1): 1-10.

Galukande M, Wabinga H, Mirembe F, Karamagi C and Asea A 2014 Molecular breast cancer subtypes prevalence in an indigenous Sub Saharan African population. Pan Afr. Med. J. 17: 249.

Gill J, Obley AJ and Prasad V 2018 Direct-toconsumer genetic testing: the implications of the US FDA's first marketing authorization for BRCA mutation testing. Jama 319(23): 2377-2378.

Gorodetska I, Inomistova M, Khranovska N, Skachkova O, Michailovich Y, Rybchenko L, Bychkova A, Stefanovich A, Klimuk B and Poluben L 2021 The reduction of two BRCA1 gene mutations frequencies in ovarian cancer patients from Ukraine. Meta Gene 29: 100900.

Hall JM, Lee MK, Newman B, Morrow JE, Anderson LA, Huey B and King MC 1990 Linkage of early-onset familial breast cancer to chromosome 17q21. Science 250(4988): 1684-1689.

Hartwig M, Janiszewska H, Bąk A, Pilarska M, Heise M, Junkiert-Czarnecka A, Laskowski $\mathrm{R}$ and Haus O 2013 Prevalence of the BRCA1 c. 68_69delAG (BIC: 185delAG) mutation in women with breast cancer from north-central Poland and a review of the literature on other regions of the country. Contemp. Oncol. 17(1): 34-37.

Huang Y, Tong Z, Chen K, Wang Y, Liu P, Gu L, Liu J, Yu J, Song F and Zhao W 2019 Interpretation of breast cancer screening guideline for Chinese women. Cancer Biol. Med. 16(4): 825-835.
Khalili-Tanha G, Sebzari A, Moodi M, Hajipoor F and Naseri M 2019 Mutations analysis of BRCA1 gene in patients with breast cancer in South Khorasan province, East Iran. Med. J. Islam. Rep. Iran 33: 105-110.

Komen SG 2017 Tanzania Breast Health Care Assessment: An assessment of Breast Cancer Early Detection, Diagnosis and Treatment in Tanzania. A report carried out on behalf of the Ministry of Health, Community Development, Gender, Elderly and Children of the United Republic of Tanzania.

Mahfoudh W, Bettaieb I, Ghedira R, Snoussi K, Bouzid N, Klayech Z, Gabbouj S, Remadi Y, Hassen E and Bouaouina N 2019 Contribution of BRCA1 5382insC mutation in triple negative breast cancer in Tunisia. $J$. Trans. Med. 17(1): 1-5.

Mansouri H, Mnango LF, Magorosa EP, Sauli E and Mpolya EA 2019 Ki-67, p53 and BCL2 expressions and their association with clinical histopathology of breast cancer among women in Tanzania. Scientific Reports 9(1): 1-11.

Miki Y, Swensen J, Shattuck-Eidens D, Futreal PA, Harshman K, Tavtigian S, Liu Q, Cochran C, Bennett LM and Ding W 1994 A strong candidate for the breast and ovarian cancer susceptibility gene BRCA1. Science 266(5182): 66-71.

Mogahed SHG, Hamed YS, Moursy YEI and Saied MHM 2020 Analysis of Heterozygous BRCA1 5382ins Founder Mutation in a Cohort of Egyptian Breast Cancer Female Patients Using Pyrosequencing Technique. As. Pac. J. Cancer Prev. 21(2): 431-438.

Mwakigonja AR, Lushina NE and Mwanga A 2017 Characterization of hormonal receptors and human epidermal growth factor receptor-2 in tissues of women with breast cancer at Muhimbili National Hospital, Dar es salaam, Tanzania. Infect. Agents Cancer 12(1): 60 .

Nickels S, Truong T, Hein R, Stevens K, Buck K, Behrens S, Eilber U, Schmidt M, Häberle L and Vrieling A 2013 Evidence of geneenvironment interactions between common breast cancer susceptibility loci and established environmental risk factors. PLoS Gen. 9(3): e1003284.

Pogoda K, Niwińska A, Sarnowska E, Nowakowska D, Jagiełło-Gruszfeld A, Siedlecki J and Nowecki Z 2020 Effects of 
BRCA Germline Mutations on TripleNegative Breast Cancer Prognosis. J. Oncol. 2020.

Reeves MD, Yawitch TM, Van der Merwe NC, Van den Berg HJ, Dreyer $G$ and Van Rensburg EJ 2004 BRCA1 mutations in South African breast and/or ovarian cancer families: evidence of a novel founder mutation in Afrikaner families. Int. $J$. Cancer 110(5): 677-682.

Roa BB, Boyd AA, Volcik K and Richards CS 1996 Ashkenazi Jewish population frequencies for common mutations in BRCA1 and BRCA2. Nature Gen. 14(2): 185-187.

Rummel SK, Lovejoy L, Shriver CD and Ellsworth RE 2017 Contribution of germline mutations in cancer predisposition genes to tumor etiology in young women diagnosed with invasive breast cancer. Breast Cancer Res. Treat. 164(3): 593-601.

Shin HC, Lee HB, Yoo TK, Lee ES, Kim RN, Park B, Yoon KA, Park C, Lee ES and Moon HG 2020 Detection of germline mutations in breast cancer patients with clinical features of hereditary cancer syndrome using a multi-gene panel test. Cancer Res. Treat. 52(3): 697-713.

Sung H, Ferlay J, Siegel RL, Laversanne M, Soerjomataram I, Jemal A and Bray F 2021 Global cancer statistics 2020: GLOBOCAN estimates of incidence and mortality worldwide for 36 cancers in 185 countries. Cancer J.Clin. 71(3): 209-249.

Szwiec M, Jakubowska A, Górski B, Huzarski T, Tomiczek-Szwiec J, Gronwald J, Dębniak T, Byrski T, Kluźniak W and Wokołorczyk D 2015 Recurrent mutations of BRCA1 and BRCA2 in Poland: an update. Clin. Gen. 87(3): 288-292.

Tikhomirova L, Sinicka O, Smite D, Eglitis J, Hodgson SV and Stengrevics A 2005 High prevalence of two BRCA1 mutations,
4154delA and 5382insC, in Latvia. Famil. Cancer 4(2): 77-84.

Uyisenga JP, Segers K, Lumaka AZ, Mugenzi P, Fasquelle C, Boujemila B, Josse C, Mutesa L and Bours V 2020 Screening of germline mutations in young Rwandan patients with breast cancers. Mol. Gen. Genom. Med. 8(11): e1500.

Waks AG and Winer EP 2019 Breast cancer treatment. Jama 321(3): 316-316.

Wong-Brown MW, Meldrum CJ, Carpenter JE, Clarke CL, Narod SA, Jakubowska A, Rudnicka H, Lubinski J and Scott RJ 2015 Prevalence of BRCA1 and BRCA2 germline mutations in patients with triple-negative breast cancer. Breast Cancer Res. Treat. 150(1): 71-80.

Wooster R, Bignell G, Lancaster J, Swift S, Seal S, Mangion J, Collins N, Gregory S, Gumbs C and Micklem G 1995 Identification of the breast cancer susceptibility gene BRCA2. Nature 378(6559): 789-792.

Yawitch T, Van Rensburg E, Mertz $\mathrm{M}$ and Falkson C 2000 Absence of commonly recurring BRCA1 mutations in black South African women with breast cancer. South Afr. Med. J. 90(8): 788-794.

Zahra LF, Cherkaoui JI, Ouldim K, Aboussair N, Jalil A, El Khalil EB, Benjaafar N and Sefiani A 2011 Genetic testing and first presymptomatic diagnosis in Moroccan families at high risk for breast/ovarian cancer. Oncol. Letters 2(2): 389-393.

Zoure AA, Slaoui M, Bambara HA, Sawadogo AY, Compaoré TR, Ouédraogo NLM, Mzibri ME, Attaleb M, Traoré SS, Simpore J and Bakri Y 2018 BRCA1 c. 68_69delAG (exon2), c. 181T> G (exon5), c. 798_799delTT and 943ins10 (exon11) mutations in Burkina Faso. J. Public Health Afr. 9(1): 663-667. 